\title{
Information, Communication and Mass Media; A Positive Outlook
}

Dr. Pradip Parajuli*

\begin{abstract}
Mass media was gifted on the Nepali soil early as one and half century ago. We have no longer history on mass media and journalism as other countries compared to the four and half century long history of world journalism, the history of Nepalese mass media and journalism is undoubtedly a recent phenomenon.The art and science of using information to one's advantage is one of the keys to influence and power in any society. As a matter of fact man alone has the capacity to generate information through new symbols, and to share the meaning of these symbols with fellow men. One may even look with advantage at human history through the information/ communication prism.

It is the history of an ever-increasing capability to create new generated information and shares it with others to their mutual advantage to ward off danger, to inform about the new opportunities, etc. In brief, information/ communication are the key to organized human life.
\end{abstract}

Keywords: Information, Communication \& Mass Media.

\section{Introduction}

Communication existed even during the most primitive times as it does now when tremendous changes have come up in this field as a result of the feats accomplished in science and technology. The art and science of using information to one's own advantage is the key to influence the society. In today's world, mass media occupies an important place on socialization process. It has contributed for emergence of public opinions and public images on important issues inthe mass society. In fact, mass media plays significant role in socialization of community's members- influencing their attitude, performance and manner.Media became powerful agent of socialization.

Information is a necessary tool for development and empowerment and that once people are able to realize the need for a better life and they are availed with the relevant information, then they will be willing to undertake that change (Shepherd, 1998 cited in Musubika, 2008, P. 11).

\footnotetext{
* Parajuli is an Associate Professor at the Department of Rural Development, T.U., Patan Multiple Campus, Patan Dhoka.
} 
Transmission of information is very necessary for individual, society and nation. Information makes people aware, provide knowledge about new things and situation, build confidence, and make people dynamic and energetic. In society transmission of information help for co-operation, share social development, influence social attitude and traditional practices and sometime create and develop conflict within society and split it in different fractions. Nation is the combination of people, society, geography, ideology and recognition. Without transmission of information, these things may not combine for a nation. After existence of a nation, its further development and identity depend on nation's information flow. The transmission of information is also necessary for nation's daily performance and maintenance (Ayadi, 2001 : 15-16).

Information is a major contributor in the progress of change and development. It is only through communication one acquires information associated to our immediate surroundings. To get information on national/international news, politics, health, science, or trade, one of the media (print/ electronic) comes into play directly or indirectly. Thus, media is the foremost source of information dissemination which considerably influences masses' opinion. Views or behaviours are based in what an individual perceives from information collected through media (Guleria, $2010: 4$ ).

To gin with men and women perhaps had only the tools of the voice, the gesture, the engraving and the painting to communicate their ideas and messages. But as human society progressed, people discovered or invented more and more efficient methods and technologies to multiply the voice, the signs and the writing for simultaneous sharing with a large number of people. The result is what we know today as the mass media- the press, the radio, the film and TV. There emerged the mass society (Yadava, $1990: 7$ ).

The word media comes from a Latin plural form for the singular noun medium. Mass media transmit messages to large audiences. A modernizing society finds mass media essential. These media help disseminate information with great speed to large numbers of people located at different places. Mass Media serve as both authoritative resources, circulating meanings that legitimate particular forms of conduct and allocate resources, producing economic value like other means of production. Equally, media production and reception are subject to specific rules of interpretation and conduct (Kharel, 2007 : 54).

Due to the work of Weber and Durkheim, development was believed to be only possible under Western influence. Development would occur through prior change in the values, attitudes and norms of the people. Webster, stated, "Development then depends on 'traditional,' ‘primitive' values being displaced by modern ones” (Webster, 1990 cited in Musubika, 2008 : 22). Mass media were to be used to disseminate ideas and encourage 
increased awareness about society and also heighten political awareness and participation in the democratic system.

The mass media are typically the prime source of information on the politics of the day (Almond, 2010 cited in Mathur, 2013 : 4). The press or the print media (newspapers and magazines) is the oldest from of the present day's mass media which came into being after the introduction of the printing press. Radio or broadcast media, television or telecast media, and Internet or web media are the other important forms of the mass media, which were originated at different point of time in the last century. However, the mass media newspapers, radio, television, internet are important in socializing altitudes and values in nations around the globe.

\section{Newspaper}

Mass media was gifted on the Nepali soil early as one and half century ago. We have no longer history on mass media and journalism as other countries compared to the four and half century long history of world journalism, the history of Nepalese mass media and journalism is undoubtedly a recent phenomenon. Jung Bahadur, the first prime minister of Rana family who virtually ruled the country for more than a century brought the first hand press in Nepal in 1851 AD from England known as Giddhe Press (Parajuli, 1996 : 7).

Gorkha Bharat Jeevan was first Nepali magazine published in 1886 A.D.; interestingly this monthly magazine was published from Banaras, India by Moti Ram Bhatta. He later set up PashupatiChapakhana (Pashupati Printing Press). It was the first non-governmental press set up in 1889 A. D. He published SudhaSagar a literary monthly which heralds a new age in Nepali Journalism. The Editor was Pandit Kapil Dev Sharma. Gorkhapatra was started in 1901 A.D. as a weekly newspaper published every Monday, during the premiership of Dev Shumshre Rana. After the establishment of democracy in 1951, new era of Nepalese journalism began. New political system and liberal administration opened the gate to the next phases of newspaper development in Nepal (ibid).

Media serves the vital function of communication in human societies. Social formation is impossible without communication. The nature and development of the technologies of communication often denote the stage of development achieved by the human society of a particular era. The development of print media was an epoch making development in human history. It has changed the history beyond recognition and brought changes to a degree unprecedented (Sivadasan, $2010: 71$ ) 
Newspapers are the first vehicle to provide information to mass audience. It has credibility and retention that no other information vehicle can provide us. They are integral part of our community in spite of being a perishable commodity (Guleria, 2010 : 98).

\section{Radio}

Radio has been the most prevalent form of mass communication in Nepal. Government owned Radio Nepal has been the sole domestic radio provider since 1951, and by 1995 it was broadcasting in short-wave, medium-wave, and FM frequencies in Nepal.

Radio development as a medium in the early 1920s.it is the most accessible mass medium anywhere in the world, shadowing people wherever they are. In the developed countries, 98 per cent of the households have several radio sets each. In the developing world, radio might not be that pervasive but it is easily the most popular, available and affordable mass medium. Transistor radios in the 1960s known also as 'the shadow medium' that made swift strides after the inauguration of the television age (Kharel, 2007, P. 59).

Although the state-run radio Nepal was the only radio service in the country for more than 40 years, the Broadcasting Act 2048 and the subsequence regulation paved the way for the private sector into the filed or radio broadcasting. Initially, the government was reluctant to issue any license to a sector, Nepal Forum of environmental journalists (NEFEJ) obtained a license to operate Radio Sagarmatha but not before Radio Nepal in 1995 started its own FM radio services that was run primarily to have a head start in the new competition.

It has failed miserably and resorts to rent-seeking by allowing the highest bidder among private companies to avail themselves of the frequency for a specific period for specific rental charges (Kharel, 2007, PP. 72-73).

Radio is a medium of communication that plays a very important role in spreading information. However, unlike other media, radio is far reaching, even in areas without electricity and areas in which people are illiterate. In addition, radio increases participation and opinion sharing and improves and diversifies knowledge and skills and caters for health and cultural needs (Phipps, 2004 cited in Musubika, 2008, P. 29).Hence, because of its unrivalled reach, radio is the best means of technology to meet the information and communication needs of the rural women, much as there has been advancement in technology. Nevertheless, there still exists a digital divide in the world and as such, radio comes in to bridge this gap (Buckley, 2006, P. 3).

Due to its easy access by rural and poor people, radio provides a channel for these people to participate in debate and to express their opinion on public policies. Without a source of 
information, these people would not know their rights and entitlements, nor would they be able to challenge certain decisions and would also lack necessary information to improve their lives (Buckley, 2006, P. 5). The need by the poor people to be heard and to be able to participate in national policies, led to the formation of a new form of radio i.e. the community radio. This kind of radio has been identified as having the ability to reach out to those that have constantly been marginalized and excluded in society (Buckley, 2006, P. 8) especially since it provides access and voice in the local languages of the people.

Radio was chosen as the medium of communication because radio was cheaper to set up compared to television. Radio reached a wider audience compared to both the print media and television. Because it built on oral traditions, radio seems to have been widely accepted in development communication (Burke, 1999, cited in Matewa,2003, P. 60). The major problem facing the use of radio for development has been the scarcity of electricity in rural areas in most developing countries (Moemeka, 1981 cited in Matewa, 2003, P. 65). The alternative source of power for the radio sets, batteries or solar, seem to be unaffordable to the majority of the rural poor. It was due to this assumption that the need for an alternative source of power to improve access to radio was desperately needed (Matewa, 2003, P. 65).

Although the importance of radio is generally recognised among those working in communication for development as a medium for communication, information and education, there are still problems which need to be addressed to make it more effective in disseminating agricultural information, health, hygiene, literacy and social information (Matewa, 2003, P. 66).

Sameer et al (2006, cited in Musubika, 2008, P. 13) observe that:

Radio can provide access to information as well as act as a platform for interactivity. Due to its extreme wide reach, it is well-placed to provide relevant information to its listeners. Radio has also been around for a long time and is one of the most important Information Technologies in many developing countries that can be used to inform a vast majority of people about issues that are necessary for their empowerment (Musubika, 2008, P. 13).

\section{Television}

Television in Nepal started with Nepal Television in January 1985. It was launched as a project under the sixth development plan (1980-1985) with the slogan "Communication for Development". It was set up with a broad mission statement, "Produce and telecast programs on educational, religious and cultural conservation to promote national unity, conserve heritage and promote national interest". It was part of a research project to study 
the feasibility of establishing television to ascertain if this was economically and technically possible. It had a monopoly for over 15 years in Nepal.

After 27 years Nepal has sixteen television broadcasters including the government run Nepal Television and NTV PLUS. The private broadcasters are: Kantipur Television owned by Kantipur Publication, Image Channel owned by Image Groups of Companies, Avenues Television owned by Avenues Ad started broadcasting from July 2007. After Avenues Television, more news Channels were launched, Sagarmatha Television, was launched in July 2007. ABC TV Nepal and National TV were launched in 2008, News 24, Himalaya Television and Mountain Television were launched in 2010. Entertainment Channels started popping in 2009 with TV Filmy, with E-24 Television launching in 2012. Regional Channels like Tarai Television,Nepal Mandal and Makalu Television started from 2010. Mission Star was launched recently. Nepal 1 is beamed from India. Channel Nepal was the first Nepali language satellite channel, which discontinued in 2011.

Television has the greatest potential for transmitting information to enormous numbers of people. The development world has time and again proved so. The world is also aware of the potential reach and use of this medium that arrived on the mass scale in the latter half of the 1940s. Till the turn of the state-owned Nepal television. More than 15 channels have obtained license to lunch their services, and seven of them are on air, including two state-run channels. This demonstrates the interest and demand for multiple channels and choice (Kharel, 2007, P. 61).

For almost two decades since it began regular transmission in 1985, Nepal Television was the only television service in the country. With the advent of the new century, things have changed dramatically for the better (Kharel, 2007, P. 61). Mass communication has always been associated with social change and development. It is considered important for attitudinal and behavioural change particularly in developing countries like ours, where the vast majority of people are still illiterate. Rapid expansion of television in recent years has boosted the importance of mass communication (Mehta, 1990, P. 129).

\section{Internet}

Internet access arrived in Nepal in the early 1990s. A private company, Mercantile Communications, began email services in 1992, and was formally registered as an ISP in 1995. However, early internet connection was slow and expensive. Nepal now has fairly good internet connectivity, except in very remote areas and areas without access to electricity. The government-owned Nepal Telecom and large number of private companies provide internet services. GSM mobile technology theoretically covers the entire county 
(although there may be some pockets where coverage is disrupted by topography) and some companies provide internet connectivity on mobile phones. Nepal has a fibre-optic cable backbone connecting the plains, districts and neighbouring India (UNESCO, 2014, P. 86).

The number of internet subscribers has swelled by 57 percent in the one-year period from mid-Aug 2011 to mid-Aug 2012, pushing the country’s internet penetration rate up to 19.32 percent. The growth is catalysed by increased demand for services like GPRS, ADSL, wireless, and optical fibre data services.

The internet and e-mail are fast becoming mass media. Some experts are against giving them the status of mass media because they lack uniformity in the messages they transmit. E-mail can connect individuals, organizations and institutions and institutions across to it. Affordability is the main factor. It has been a growing channel of communication even in developing countries but it will be many more before its use becomes common among literate populations in these countries (Kharel, 2007, P. 64).

The internet and e-mail services are inching their way for deeper penetration of the urban centres Nepal. However, it will takes several decades, if not more, for them to reach most educational institutions, government offices and private sector for information, business, entertainment or personal communication (ibid).

The internet is being seen as the 'magic bullet', a solution to all the problems of development. Yet the rapid increase in the use of the internet in developing countries is largely an urban phenomenon (Richardson, 1999, P. 1). Richardson (1999) explains why the internet is an important medium that rural and agricultural development activists should not ignore as it could be used for bottom-up, horizontal and top-down communication.

Anderson et al., (1999) acknowledges that direct access to the internet by rural communities, is not feasible. They therefore suggest that a link should be established through, for example, extension services.

Although the emphasis in developed countries has been on the personal computer and personal access to the Internet, this situation is not feasible in rural areas of the developing world, at present. Therefore, the link between ICTs and local people will, most likely, have to be made through existing communication channels, such as extension agents, NGO workers and rural teachers. Attention to creating and sustaining these linkages will be crucial to ensure that ICTs reach their potential as tools for development. In this regard, it is important to direct attention to how tele center infrastructure and technology can best be configured or organized to facilitate group use (Anderson et al, 1999, P. 1). 


\section{Conclusion}

The modern Information Communication Technologies (ICTs) is the most important tools for the development of any society.In today's world, mass media occupies an important place. It contributes towards the emergence of a mass society and mass culture. In a mass society, public opinion and images on various important issues are shaped to a great extent by the mass media. In a democratic society like ours, public opinion influences public life and governance.Communication for development assumed that Mass Media was rapid and more efficient in transmitting information. Modern communication media make it possible for millions of people throughout the world to be in touch with nearly any spot in the globe.

\section{References}

Anderson, J., Van Crowder, L., Dion, D., \& Truelove, W. (1999).Applying the lessons of participatory communication and training to rural telecasters. Special: The first mile of connectivity. Retrieved May 13, 2014, from http://www.fao.org/docrep/x0295e/x0295e16.htm

Ayadi, A. B. (2001). Role of Mass Media on Nepal-India Relations: A Content Analysis of Selected Nepali and Indian Newspapers on the Trade Embargo (1989) and the Mahakali Treaty (1996). Unpublished Master's thesis.Tribhuvan University, Nepal.

Buckley, S. (2006). Community Radio and Empowerment. Unpublished paper presented on World Press Freedom Day. Paris: UNESCO.

Guleria, N. (2010). Print Media and Women Empowerment.Unpublished doctoral thesis, Punjabi University, India.

Kharel, P. (2007). Dimensions of Communication.Kathmandu: Nepal Association of Media Educators.

Matewa, C. E. F. (2003). Media and the empowerment of communities for social change.Unpublished doctoral thesis, University of Manchester, UK.

Mathur, C. K. (2013). Mass Media and Democracy in India: A Political Study of Their Relationship in Post-Emergency Period. Unpublished doctoral thesis, University of Delhi, India.

Mehta, P. (1990). Media and emerging activism for change.In Communication 2000 AD. New Delhi: Indian Institute of Mass Communication.

Musubika, J. (2008). Community Media and the Empowerment of Rural Women in Uganda: A Study of Mama FM Radio. Unpublished Master's thesis, University of Oslo, Norway.

Parajuli, P. (1996). Evolution of Mass Media in Nepal. Kathmandu: Saujanya Publications.

Shivadasan, V. (2010). Agrarian Problems and the Role of Media and Literature in Kerala with Special Reference to Socio-Economic Transformation 1934-1971. Unpublished doctoral thesis, Kannur University, India.

UNESCO (2014).Assessment of Media Development in Nepal. Kathmandu: UNESCO.

Yadava, J. S. (1990). Social Effects of Mass Media and Their Policy Implications for Third World Plural Societies.In Communication 2000 AD (pp. 7-16), New Delhi: Indian Institute of Mass Communication. 